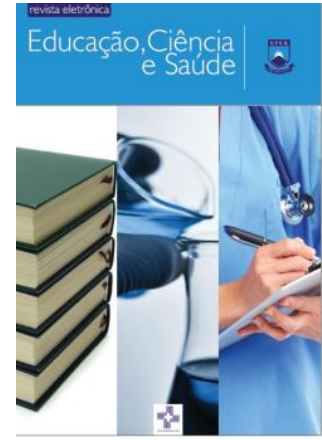

EDUCAÇÃO CIÊNCIA E SAÚDE

http://dx.doi.org/10.20438/ecs.v8i1.357

\title{
JOGO DIDÁTICO PARA O ENSINO DE ENZIMAS
}

\author{
Keila Pessoa de Oliveira ${ }^{1}$, Yanara Alessandra Santana Moura ${ }^{2}$, Ariadne \\ Tennyle Vieira de Souza ${ }^{3}$, Karoline Mirella Soares de Souza ${ }^{3}$, Ana Lúcia \\ Figueiredo Porto², Raquel Pedrosa Bezerra ${ }^{2 *}$ \\ 1 Programa de Pós-Graduação em Neuroeducação, Faculdade Descomplica, Brasil. \\ ${ }^{2}$ Departamento de Morfologia e Fisiologia Animal, Universidade Federal Rural de Pernambuco \\ (UFRPE), Rua Dom Manoel de Medeiros, 52171-900, Recife - PE, Brasil. \\ ${ }^{3}$ Programa de Pós-Graduação em Ciências Biológicas (PPGCB), Universidade Federal de \\ Pernambuco (UFPE), Avenida Professor Moraes Rego, 50670-901, Recife - PE, Brasil. \\ Email para correspondência: raquel.pbezerra@ufrpe.br
}

\begin{abstract}
Resumo
A bioquímica é complexa, extensa e de caráter interdisciplinar. $O$ ensino tradicional gera uma disciplina decorativa e desinteressante. O jogo lúdico caracteriza-se como ferramenta para auxiliar na construção do conhecimento e desenvolvimento cognitivo e social. O objetivo foi elaborar e avaliar um jogo lúdico sobre enzimas visando uma aprendizagem colaborativa e divertida. A atividade tem como público alvo discentes de nível superior. O jogo de tabuleiro é composto por materiais simples, de baixo custo e fácil acesso. Questionário constituído por cinco questões objetivas foi utilizado para avaliar o jogo. Observou-se entusiasmo, motivação e troca de conhecimentos entre discentes durante o jogo. Após análise dos questionários, observou-se que os discentes aprovaram o jogo como ferramenta complementar no estudo da estrutura química, organização tridimensional e função de enzimas, visto que a maioria dos estudantes entrevistados concordaram que o jogo melhorou a aprendizagem sobre enzimas, além de incentivar os estudos sobre o tema. Esses resultados caracterizam o jogo como uma importante estratégia didática de baixo custo facilitando o acesso e tornando viável seu uso em diferentes níveis de ensino.
\end{abstract}

Palavras-chave: bioquímica, didática, aprendizagem

\section{Abstract / resumen / résumé}

Biochemistry is a complex, extensive and interdisciplinary discipline. Traditional education creates a decorative and uninteresting discipline. The game is characterized as a tool to assist in the construction of knowledge and in cognitive and social development. Thus, the aim was to develop and evaluate a game about enzymes, enabling collaborative, motivating and fun learning. The activity is aimed at graduate students. The board game consists of simple materials, low cost and easy access. A quiz consisting of five objective questions was used to evaluate the game. There was an enthusiasm, motivation and exchange of knowledge among students during the game. After analyzing the quiz, it was observed that the students approved the use of the game as a complete tool in the study of chemical structure, three-dimensional organization, and enzyme function since the most of interviewed students agreed that the game improved the learning about enzymes 
and encouraged researches regarding this theme. These results characterized the game as an important didactic strategy with low cost, which facilitates access and makes its use feasible at different teaching levels.

Keywords: biochemistry, didacticism, learning

\section{Introdução}

A bioquímica está presente na grade curricular de todos os cursos de graduação das áreas de ciências biológicas, agrárias e da saúde. Essa disciplina faz parte do ciclo básicos e tem caráter interdisciplinar, integrando conhecimentos de biologia, química e física (PINHEIRO; DA SILVA; DE SOUZA, 2009). Vargas (2001) e Yokaichiya; Galembeck; Torres (2004) afirmaram que os discentes caracterizam a bioquímica como um conjunto de reações e estruturas químicas desvinculados da prática profissional e de difícil compreensão.

A bioquímica envolve conteúdos complexos e abstratos e, muitas vezes, de difícil compreensão. Ainda hoje, a abordagem tradicional do processo educativo prevalece na transmissão-recepção de informações, dissociando o conteúdo e realidade e dificultando o aprendizado. De acordo com a perspectiva freiriana, a educação deve ser e acontecer como:

Freire (2005, p. 67): "[...] um processo incessante, inquieto e, sobretudo, permanente de busca ao conhecimento não sendo simplesmente caracterizada pela transmissão acrítica e apolítica do conhecimento".

Conforme proposto por Piaget, o educador precisará sempre pensar se sua prática está criando situações que despertem a atenção, a curiosidade e o esforço do aluno. Deve estar sempre atento a esses aspectos, visto que uma das suas funções é criar situações de conflitos cognitivos, levando os discentes a terem experiências compatíveis com suas possíveis previsões (MONTEIRO; CHIARO, 2012),

Kishimoto (1996) relata que o professor deve rever a utilização de propostas pedagógicas, passando a adotar em sua prática aquelas que atuem nos componentes internos da aprendizagem, pois estes não podem ser ignorados quando o objetivo é a apropriação de conhecimentos por parte do aluno. Uma forma de superar esse obstáculo é propondo atividades lúdicas, como a utilização de jogos. 
Segundo Miranda (2001), mediante o jogo didático, vários objetivos relacionados à cognição (desenvolvimento da inteligência e da personalidade, fundamentais para a construção de conhecimentos); afeição (desenvolvimento da sensibilidade e da estima e atuação no sentido de estreitar laços de amizade e afetividade); socialização (simulação de vida em grupo); motivação (envolvimento da ação, do desfio e mobilização da curiosidade) e criatividade podem ser atingidos. Assim, considera-se que a apropriação e a aprendizagem significativa de conhecimentos são facilitadas quando tomam a forma aparente de atividade lúdica, pois os alunos ficam entusiasmados quando recebem a proposta de aprender de uma forma mais interativa e divertida, resultando em um aprendizado significativo.

O jogo didático é aquele formado com interesse de proporcionar determinadas aprendizagens, diferenciando-se do material pedagógico por conter o aspecto lúdico (CUNHA, 1988). Segundo Gomes (2003), a ação de jogar contribui com o processo de aprendizagem. O jogo lúdico consegue preencher muitas lacunas deixadas pelo processo de transmissão-recepção de informações, permitindo que os alunos construam seus próprios conhecimentos através do trabalho em grupo, realizando a transmissão de conhecimentos prévios a outros alunos e utilizando essas informações prévias para a construção de conhecimentos novos e mais elaborados.

Poucos jogos como o Sintetizando Proteínas, Bioquim4 x, Twister Proteico e um jogo virtual do projeto Foldit (CARVALHO et al. 2014; FARKUH; PEREIRA-LEITE et al. 2014; WEYH; CARVALHO; GARNERO, 2015; SCHAEFFER; ANGOTTI et al. 2016) estão disponíveis como ferramentas de ensino em bioquímica para nível superior. Nesse contexto, há uma necessidade de aumentar a oferta e popularizar a utilização desse recurso para estimular a aprendizagem dos discentes. Desta forma, o objetivo do presente trabalho é propor um jogo lúdico sobre estrutura química, organização tridimensional e função das enzimas para que os discentes universitários matriculados na disciplina de bioquímica do curso de Licenciatura em Ciências Biológicas da Universidade Federal Rural de Pernambuco (campus Sede) possam aprender e/ou revisar o assunto utilizando o aprendizado colaborativo e visando uma proposta de trabalho diferenciada. 


\section{Metodologia}

\subsection{Material}

O jogo é constituído de dados, peões (representados pelos próprios discentes), um tabuleiro de TNT (Figura 1), cartões-pergunta e cartões-resposta (Figura 2). Os materiais utilizados são de fácil aquisição para facilitar a elaboração do jogo. Cada casa possui uma pergunta. $O$ jogo é composto por duas fichas: uma com perguntas e outra com respostas, sendo ambas feitas com papel ofício de tamanho A4. A dinâmica do jogo foi baseada e adaptada de outros jogos populares e clássicos como "Amarelinha" e alguns outros jogos de tabuleiro.

\subsection{Preparo inicial}

O jogo foi planejado de acordo com o tempo de aula, com o perfil da turma e com a quantidade de alunos e teve tempo de duração média de $1 \mathrm{~h}$. Para que este jogo pudesse ser elaborado, foi preciso haver domínio do conteúdo além do auxílio de um professor-orientador com experiência no assunto.

O tabuleiro deve ser colocado em um ambiente espaçoso e silencioso para que todos os jogadores possam ouvir e entender com facilidade as perguntas e respostas durante o jogo. $O$ jogo pode ocorrer em equipe ou individualmente.

\subsection{Regras}

- São necessários, no mínimo, 4 participantes: no mínimo 2 no tabuleiro funcionando como "pino"; 1 com as perguntas e respostas do jogo e 1 como juiz;

- Cada participante que se comporta como um pino deve escolher o nome de uma enzima para que seja por ele representada. Exemplo: sacarase.

- O juiz e a pessoa que fica com as perguntas e respostas não podem ter essas funções e, simultaneamente, serem pinos;

- A pessoa que fica com as perguntas e respostas não pode comparar as respostas do participante com as respostas de sua ficha. Compete ao juiz fazer isso;

- Caso o aluno que desempenhe a função de juiz possua dúvidas, este pode recorrer ao professor e/ou material do assunto; 


\section{INÍCIO}

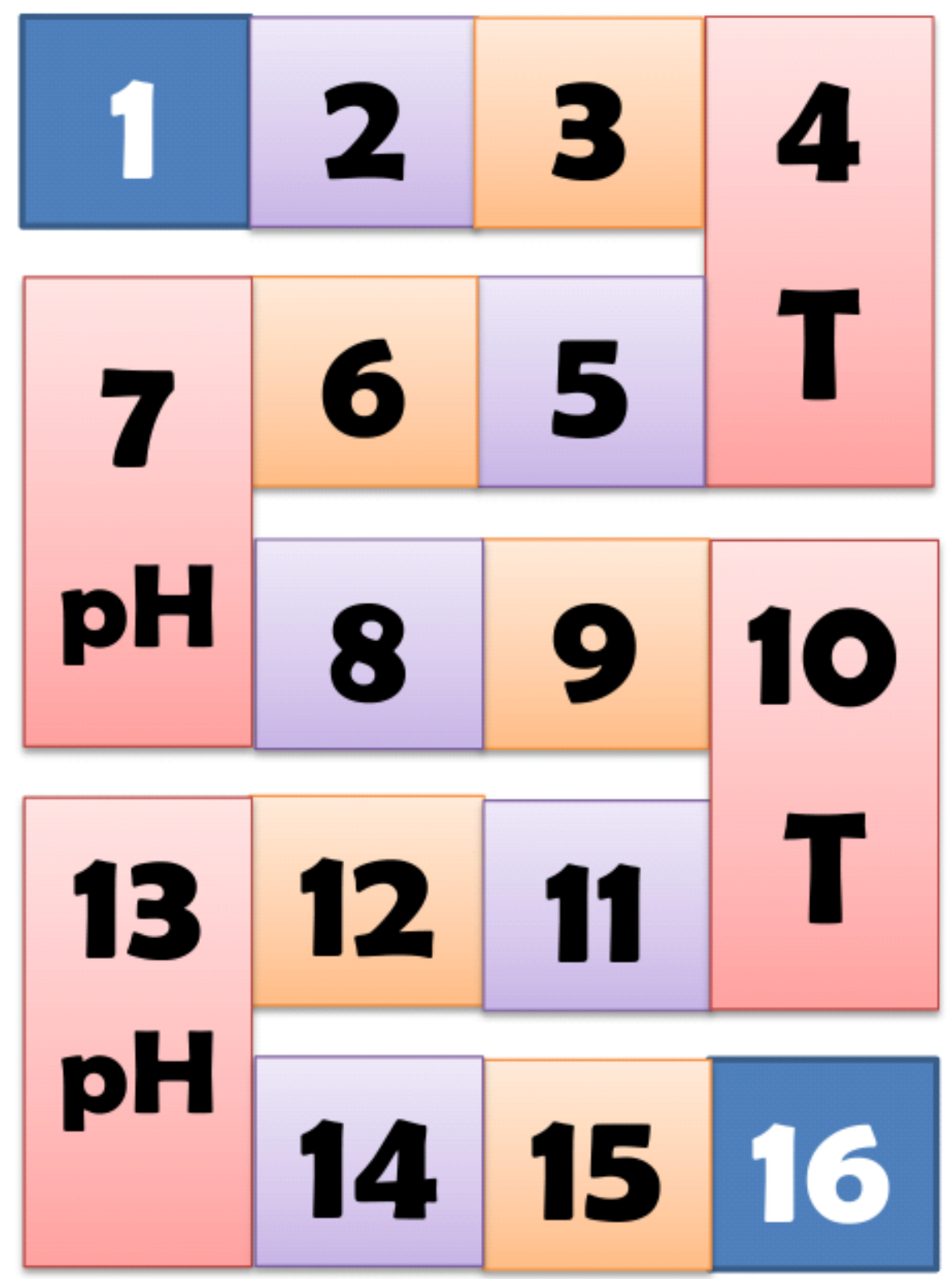

\section{CHEGADA}

Figura 1: Modelo do tabuleiro do jogo.

Fonte: Os autores (2021)

- Cada pessoa que está representando um pino tem direito de lançar o dado uma vez a cada rodada, exceto se este cair em uma casa com alguma pergunta que não tenha respondido corretamente, pois isso o impossibilita de jogar a próxima rodada;

- Caso o participante caia numa casa que a pergunta já foi respondida corretamente, não há necessidade de se repetir a resposta. Entretanto se o indivíduo cair numa casa em que a pergunta já foi feita anteriormente, mas 
não tenha sido respondido corretamente por seu colega, o participante da vez pode tentar respondê-la;

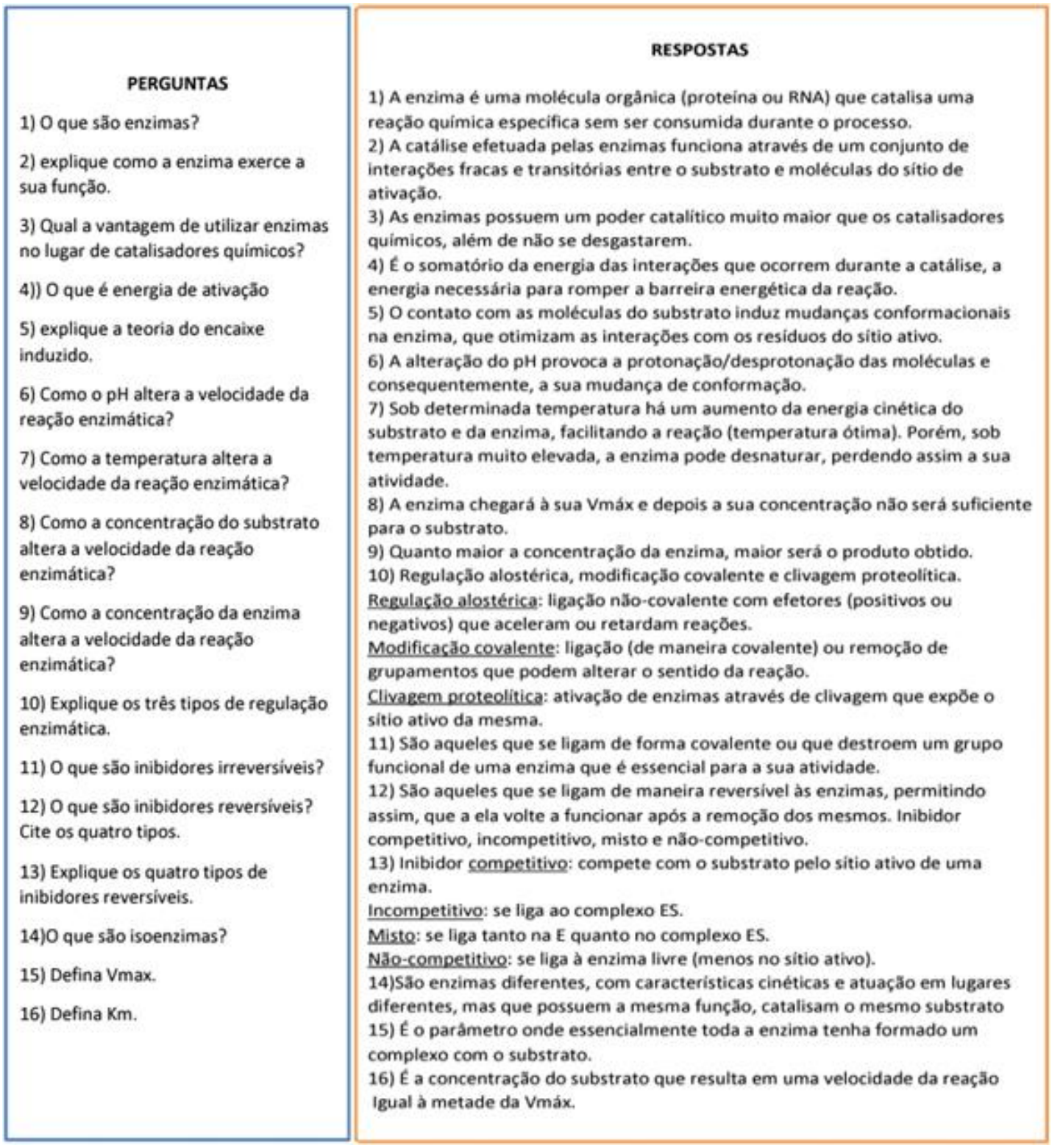

Figura 2: Exemplos dos cartões-perguntas e cartões-respostas no jogo.

Fonte: Os autores (2021)

- Caso caia no pH ideal ou temperatura ideal da enzima que o mesmo representa, ele se elevará em duas casas no jogo;

- Nenhum participante pode interferir no movimento do dado se ele já estiver sido lançado;

- Não pode haver "sopro" de respostas;

- Caso o tempo da partida determinada inicialmente pelos jogadores acabe e 
ninguém tenha alcançado a chegada, quem estiver mais à frente na partida, será o vencedor.

Sugestões para grandes grupos:

- Caso o jogo seja aplicado em um grande grupo (ex.: sala de aula), é necessário que haja, no mínimo, duas equipes. Cada equipe deve escolher um representante para ser o pino e nomear seu grupo com um nome de uma enzima;

- Todas as equipes presentes no jogo devem opinar para escolher a pessoa que será o juiz e a que ficará com as fichas de perguntas e respostas;

- A pessoa que for o pino pode recorrer à sua equipe no máximo 3 vezes para obter ajuda para responder perguntas distintas;

Os jogadores devem ficar atentos também às regras mencionadas anteriormente (quando o jogo é realizado sem a formação de equipes).

\subsection{Avaliação do jogo}

Os questionários foram elaborados por um grupo de discentes da mesma turma sob supervisão de um professor-orientador. O objetivo foi verificar a qualidade do jogo, a necessidade de alterações, o nível de agrado dos alunos e a eficácia do jogo, possibilitando uma futura modificação.

Trinta e sete estudantes do primeiro período de ciências biológicas e cursando a disciplina de bioquímica na Universidade Federal Rural de Pernambuco, responderam de forma voluntária e anônima a um questionário contendo seis questões, onde as cinco primeiras correspondiam à caracterização da amostra, com afirmativas para serem analisadas de acordo com a escala de Likert, possibilitando observar a opinião dos alunos em relação ao jogo. A última questão era aberta para comentários e sugestões sobre o jogo. A escala de Likert contemplou as seguintes opções de resposta:

1: Discordo Fortemente

2: Discordo

3: Não Tenho Opinião

4: Concordo

5: Concordo Fortemente 
O jogo foi apresentado outros discentes da mesma turma com a leitura de suas regras. A escolha por propor um número restrito de participantes foi devido a possibilidade de avaliar melhor o comportamento dos alunos enquanto jogavam, o que seria mais difícil se jogassem em equipes. Os alunos demoraram cerca de 40 minutos para terminar o jogo e, após isso, responderam ao questionário composto por cinco questões objetivas com uma linguagem de fácil compreensão para facilitar o desenvolvimento de suas respostas.

A distribuição das respostas entre os itens foi calculada como percentual de respostas em relação ao total de alunos participantes. Esses resultados foram apresentados em gráficos.

\subsection{Caracterização da amostra}

A utilização do jogo durante as aulas de bioquímica molecular ocorreu no $2^{\circ}$ semestre de 2017 com a participação de 37 alunos voluntários de faixa etária variando entre 16 e 27 anos, cursando o primeiro período do curso de Licenciatura em Ciências Biológicas da Universidade Federal Rural de Pernambuco localizada em Recife-PE. As ações relacionadas com a produção do jogo foram desenvolvidas como atividade extraclasse.

\section{$3 \quad$ Resultados e discussão}

As respostas dos questionários foram analisadas e representas em figuras enumeradas de 3 a 7. A Figura 3 mostra que $64,9 \%$ dos discentes concordaram fortemente e $35,1 \%$ concordaram que o jogo lúdico melhorou a aprendizagem sobre enzimas, mostrando que o jogo pode ser utilizado como uma ferramenta alternativa para o ensino-aprendizagem de conceitos abstratos e complexos. Os jogos utilizados após a aula teórica de determinado conteúdo permitem a revisão de conteúdos e aplicação da teoria na prática (GRÜBEL; BEZ, 2006). Bernardo et al. (2016), Campos; Bortoloto; Felício (2003) e Ventura; Ramanhole; Moulin (2016) relataram que o jogo proporciona o entretimento além de estimular uma autoanálise do conhecimento adquiro previamente. No entanto, a simples implementação dos jogos como única ferramenta didática não garante a aprendizagem, e por isso, deve estar associado a outras ferramentas didáticas. Adicionalmente, os jogos não devem 
ser apenas lúdicos, mas principalmente educativos. Da Silva et al. (2015) afirma que o discente aprende quando faz uso do raciocínio, da descoberta e da busca, por isso os jogos são considerados ambientes de aprendizagem.

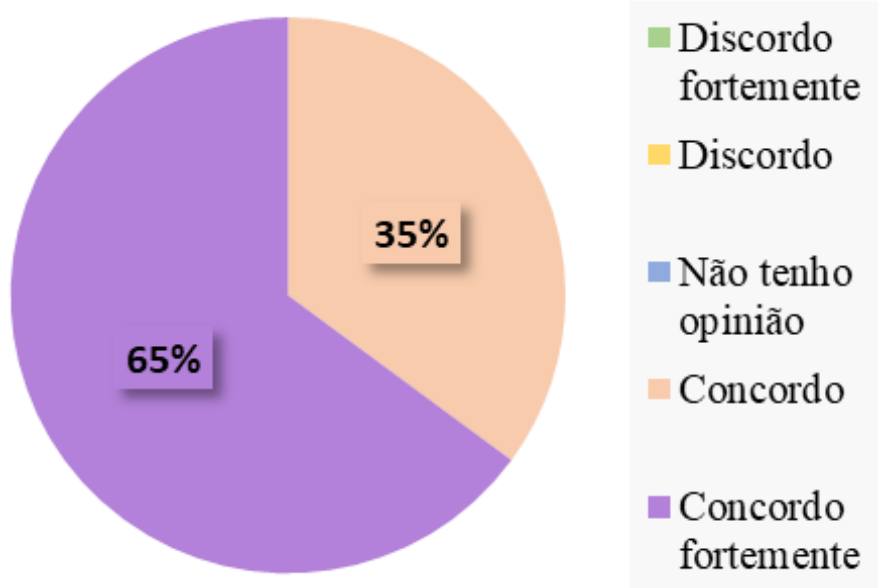

Figura 3: Distribuição percentual das respostas dos alunos de acordo com a escala de Likert referente à pergunta "O jogo melhorou a aprendizagem".

Fonte: Os autores (2021)

Fortuna (2003) relata que "enquanto joga, o aluno desenvolve a iniciativa, a imaginação, o raciocínio, a memória, a atenção, a curiosidade e o interesse, concentrando-se por longo tempo em uma atividade". Esse comportamento pode ser observado na Figura 4, onde $78,4 \%$ dos discentes concordaram que 0 material lúdico serve para o desenvolvimento cognitivo e social. Notoriamente, as atividades lúdicas, como as brincadeiras, os brinquedos e os jogos são reconhecidos pela sociedade como meio de fornecer ao indivíduo um ambiente agradável, motivador, prazeroso, planejado e enriquecido possibilitando a aprendizagem de várias habilidades. Outra importante vantagem no uso de atividades lúdicas é a tendência em motivar o aluno a participar espontaneamente na aula. Acrescenta-se a isso, o auxílio do caráter lúdico no desenvolvimento da cooperação, da socialização e das relações afetivas e a possibilidade de utilizar jogos didáticos de modo a auxiliar os alunos na construção do conhecimento em qualquer área. O jogo didático possui natureza lúdica e educativa em equilíbrio, desafios para os alunos resolverem, exercita habilidades cognitivas e motoras do jogador-aluno, bem como o descobrimento de conceitos, além de ter aspectos interativos e dinâmicos (ARROYO, 2013). A utilização de jogos didáticos foi benéfica para a aprendizagem cognitiva, para o desenvolvimento social e estimula a motivação 
social e emocional permitindo que o aluno se sinta mais à vontade em participar visto que está envolvido em seu grupo afetivo, diminuindo sua hesitação em errar, aprendendo com os erros e encorajando-se a tentar acertar posteriormente. Os alunos sentem-se mais descontraídos por serem avaliados através de jogos ao invés de outros tipos de avaliação, como a prova escolar (ALENCAR et al. 2019)

Da Silva et al. (2015, p. 31): "[...] o jogo não representa apenas as experiências vividas, mas prepara o indivíduo para o que está por vir, exercitando habilidades e principalmente estimulando o convívio social".

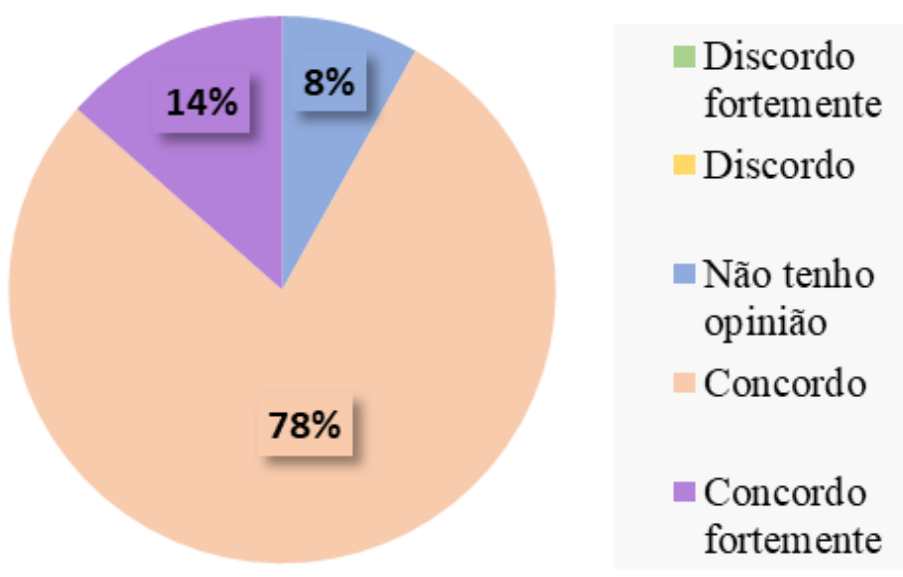

Figura 4: Distribuição percentual das respostas dos alunos de acordo com a escala de Likert referente à pergunta "Jogo contribuiu para o desenvolvimento cognitivo e social" Fonte: Os autores (2021)

Muitos docentes ensinam a bioquímica a partir de uma abordagem desconexa da prática profissional, fazendo da bioquímica uma disciplina mecânica, conteudista e sem correlação com as demais disciplinas do ciclo básico (REGIS et al ., 2001; PINHEIRO; DA SILVA; DE SOUZA, 2009). Outro problema que surge entre os discentes é a dificuldade em abstrair e imaginar as estruturas químicas, uma vez que a bioquímica exige tais capacidades para a compreensão dos fenômenos moleculares (HEIDRICH, et al., 2010). Nesse contexto, $54,1 \%$ concordaram fortemente e $37,8 \%$ concordaram que o jogo torna a aprendizagem mais atrativa (Figura 5), como comentado pelo aluno A: "Parabéns pela iniciativa, o jogo tornou o assunto mais legal e divertido". O jogo didático é uma importante ferramenta que possibilita maior interação social, desperta a criatividade e potencializa o raciocínio lógico (ALENCAR et al. 
2019). Campos; Bortoloto; Felicio (2003), aliar os aspectos lúdicos aos cognitivos favorece a motivação interna, o raciocínio, a argumentação e a interação entre alunos e entre professores e alunos. De modo geral, os jogos lúdicos são, para os alunos, atividades mais significativas das situações de aprendizagem escolar do que os tradicionais exercícios (FERREIRA, 1998, p. 50).

Dois discentes não tiveram opinião e um discordou. $\mathrm{O}$ aluno $\mathrm{B}$ comentou "O jogo foi muito bom, mas queria sugerir que houvesse mais perguntas". Isso mostra que os cartões-perguntas precisam ser melhorados em relação a qualidade e quantidade, visando motivar e incentivar os discentes. Mas não significa dizer que não tenha sido importante, pois conforme Da Silva et al. (2015, p. 29) "[...] vale defender que cada jogo, por mais simples que seja está cheio de aprendizados de funções essenciais ao desenvolvimento cognitivo do ser humano".

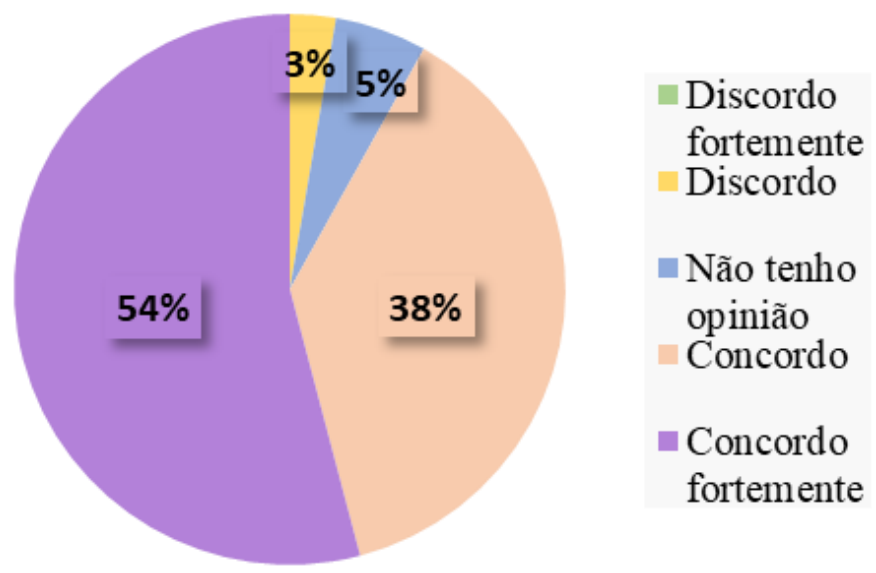

Figura 5: Distribuição percentual das respostas dos alunos de acordo com a escala de Likert referente à pergunta "A utilização do jogo incentivou o estudo sobre enzimas" do questionário.

Fonte: Os autores (2021)

Como mostra na Figura 6, 59,5\% concordaram fortemente e $40,5 \%$ concordaram que o jogo facilitou a aprendizagem sobre estrutura química, organização tridimensional e função das enzimas, mostrando que o jogo é adequado para revisão do assunto. 


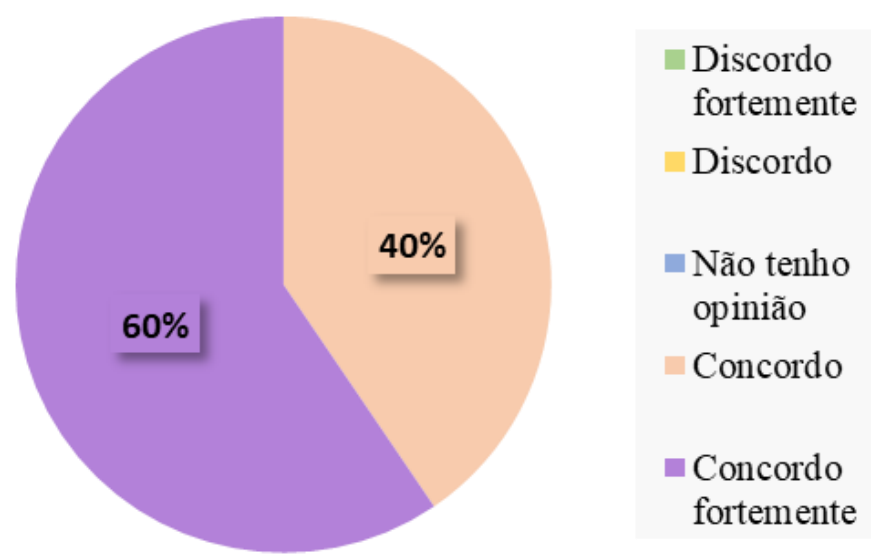

Figura 6: Distribuição percentual das respostas dos alunos de acordo com a escala de Likert referente à pergunta "o jogo contempla a estrutura química, organização tridimensional e função de enzimas" do questionário.

Fonte: Os autores (2021)

A cooperação e a interação no grupo social são fontes de aprendizagem. A maioria dos participantes $(59,9 \%)$ reconheceu que a troca de conhecimentos necessários ao decorrer do jogo aumentou a compreensão do conteúdo (Figura 7). O jogo proporciona a interação dos alunos com os seus colegas e contribui para melhorar o relacionamento entre os mesmos, possibilitando o estímulo à participação e o interesse nas aulas e assuntos. Isso permite que o discente aprenda de forma prazerosa e em um contexto desvinculado da situação de aprendizagem formal. A utilização do jogo torna possível uma prática educativa que fomenta a interação de grupos heterogêneos e a interação de indivíduos em diferentes níveis de competência (MONTEIRO; CHIARO, 2012).

A utilização dos jogos didáticos após as aulas teóricas melhora a motivação e envolvimento dos alunos no processo educacional uma vez que atua como um momento de descontração, reforço dos conteúdos e síntese do conhecimento (ALENCAR et al. 2019). Ademais, o jogo didático é capaz de fechar muitas lacunas deixadas pelo modelo tradicional de transmissãorecepção de informações e conceitos (GRÜBEL; BEZ, 2006; JORGE et al. 2009; SILVA, 2016). Kishimoto (1996) relata que o jogo desenvolve além da cognição, ou seja, a construção de representações mentais, a afetividade, as funções sensório-motoras e a área social. 


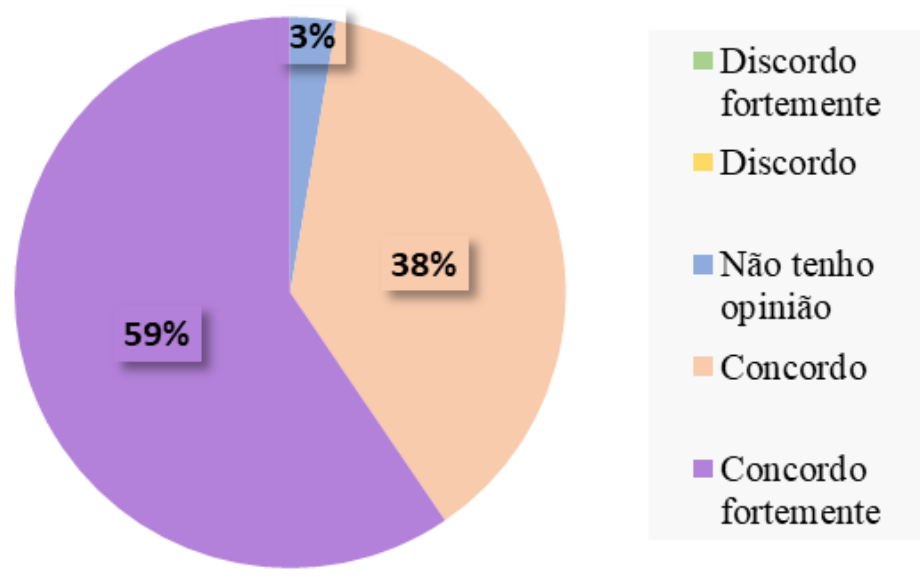

Figura 7: Distribuição percentual das respostas dos alunos de acordo com a escala de Likert referente à pergunta "troca de conhecimento entre os participantes aumenta a compressão do conteúdo" do questionário.

Fonte: Os autores (2021)

De um modo geral, o jogo foi avaliado positivamente. Grübel; Bez (2006) relatam que as atividades práticas tornam as aulas mais prazerosas $\mathrm{e}$ fascinantes, fazendo com que os alunos se sintam motivados a participar da atividade, aprender em grupo, não ter medo de errar e buscar a autoaprendizagem. O jogo obteve também características bem dinâmicas, proporcionando o aprendizado sobre enzimas através da brincadeira, de uma maneira divertida e prazerosa. Os comentários apresentados pelos alunos indicaram que os alunos perceberam a importância do jogo em propiciar o desempenho e a aprendizagem, levando em consideração o estímulo que o jogo causou na sala de aula. Nenhum aluno mencionou não ter gostado do jogo.

Outro fator importante relatado pelos discentes foi a prática de realizar trabalho em grupo justificado pela importância de um auxiliar o outro, a possibilidade de discutir e complementar suas experiências e saberes com os dos outros e divertir-se, o que aumenta os laços entre os mesmos, além da troca de conhecimento entre eles. Essa integração constitui-se em estímulo para a sala. Assim, o jogo auxilia na aprendizagem como uma forma de revisão do assunto, bem como ensina tópicos em que os alunos não haviam aprendido muito bem. 


\section{Conclusão}

O jogo sobre enzimas é uma importante estratégia no processo de ensino-aprendizagem, principalmente quando relacionado a conceitos abstratos e complexos, favorecendo a aquisição e retenção de conhecimentos em clima de alegria e prazer. O educador pode utilizá-lo para aperfeiçoar sua prática educativa, estimulando os alunos a motivação interna, raciocínio, argumentação e a interação entre os participantes. É evidente que o jogo não irá sanar todos os problemas que cercam a educação, porém não há dúvidas de que alguns óbices na aprendizagem podem ser subtraídos ao usar essa atividade lúdica. A utilização de jogos lúdicos deveria ocupar um espaço e um tempo maior na prática pedagógica cotidiana dos professores.

O recurso didático utilizado é de baixo custo o que facilita o acesso, bem como poderia se adaptado a diferentes realidades e a outros níveis de ensino, sem perder o caráter lúdico e educativo. Entretanto, a mudança é gradual e precisa de tempo para ocorrer.

\section{Referências}

ALENCAR, G. M. et al. Utilização de Jogos Didáticos no processo de ensinoaprendizagem em biologia. In: III Congresso Nacional de Educação, 2019, Areté. Anais. Areté: Editora Realize, 2019.

ARROYO, M. G. Outros sujeitos. Outras Pedagogias. Petrópolis, RJ: Vozes, 2012.

BERNARDO, R. D. C. F. et al. A importância dos jogos didáticos como ferramenta pedagógica nas aulas de biologia. In: III Congresso Nacional De Educação, 2016, Areté. Anais. Areté: Editora Realize, 2016.

CAMPOS, L. M. L.; BORTOLOTO, T.; FELÍCIO, A. A produção de jogos didáticos para o ensino de Ciências e Biologia: uma proposta para favorecer a aprendizagem.

Caderno dos Núcleos de Ensino, v. 47, p. 35-48, 2003.

CARVALHO, J. C. Q. D. et al. "Sintetizando Proteínas", o jogo: proposta e avaliação de uma ferramenta educacional. Revista de Ensino de Bioquímica, v. 12, n. 1, p. 49-61, 2014. Disponível em: <https://doi.org/10.16923/reb.v12i1.328.> 
CUNHA, N. H. S. Brinquedo, Desafio e Descoberta. Rio de Janeiro: Fae, 1988.

DA SILVA, E. G. et al. Jogos interativos: uma abordagem metodológica para auxiliar no processo ensino aprendizagem dos alunos do 60 e 70 anos na Escola Campos Sales em Juscimeira / MT. Revista Monografias Ambientais, v. 14, p. 23-40, 2015.

FARKUH, L.; LEITE, C. P. Bioquim4x: um jogo didático para rever conceitos de bioquímica. Revista de Ensino de Bioquímica, v. 12, n. 2, p. 1-18, 2014.

FERREIRA, M. A. O jogo no ensino de ciências: limites e possibilidades. Dissertação (Mestrado), Universidade Federal de Santa Maria, Santa Maria, 1998.

FORTUNA, T. R. Sala de aula é lugar de brincar? In: Planejamento em destaque: análises menos convencionais, XAVIER, M. L. M.; ZEN, M. I. H. D. (org), Porto Alegre: Mediação, 2000.

FREIRE, P. Pedagogia da autonomia: Saberes necessários à prática educativa. 33. ed. Rio de Janeiro: Paz e terra, 2005.

GOMES, M. A. M. A utilização dos jogos na educação - diferentes abordagens. Argumento, v. 5, n. 10, p. 119-131, 2003.

GRÜBEL, J. M.; BEZ, M. R. Jogos Educativos. Revista Novas Tecnologias na Educação, v. 4, n. 2, p. 1-7, 2006.

HEIDRICH, D. N.; ANGOTTI, J. A. P. Implantação e avaliação de ensino semipresencial em disciplinas de bioquímica utilizando ambiente virtual de aprendizagem. Revista de Ensino de Bioquímica, v. 8, n. 1, p. 45-58, 2010.

JORGE, V. L. et al. Biologia limitada: um jogo interativo para alunos do terceiro ano do ensino médio. In: VII ENCONTRO NACIONAL DE PESQUISAS EM EDUCAÇÃO E CIÊNCIAS, 2009, Florianópolis. Anais.Florianópolis: 2009.

KISHIMOTO, T. M. Jogo, brinquedo, brincadeira e a educação. São Paulo: Cortez, 1996. 
MIRANDA, S. D. No fascínio do jogo, a alegria de aprender. Ciência Hoje, v. 8, n. 14, p. 21-34, 2001.

MONTEIRO, C.; CHIARO, S. D. Fundamentos Psicológicos do Ensino e da Aprendizagem. Recife: Editora Universitária UFPE, 2012.

PINHEIRO, T. D. L. et al. Ensino De Bioquímica Para Acadêmicos De Fisioterapia: Visão e Avaliação do Discente. Revista de Ensino de Bioquímica, v. 7, n. 1, p. 1-11, 2009. Disponível em: <https://doi.org/10.16923/reb.v7i1.35.>

REGIS, W. C. B.; GONÇALVES, M. L.; SANTRORO, M. M. Avaliações de um curso prático de bioquímica como ferramenta auxiliar ao ensino teórico em cursos profissionalizantes. Revista de Ensino de Bioquímica, v. 2, p. 2, 2001.

SCHAEFFER, A. G.; ANGOTTI, J. A. P. Jogos digitais na apropriação de conhecimentos científicos. Revista Novas Tecnologias Na Educação (RENOTE), v. 14, n. 1, p. 1-10, 2016.

VARGAS, L. H. M. A Bioquímica e a Aprendizagem Baseada em Problemas. Revista de Ensino de Bioquímica, v. 1, n. 1, p. 1-5, 2001. Disponível em:

$<$ https://doi.org/10.16923/reb.v1i1.5.>

VENTURA, J. P.; RAMANHOLE, S. K. D. S.; MOULIN, M. M. A importância do uso de jogos didáticos como método facilitador de aprendizagem. In: XX Encontro Latino Americano de Iniciação Científica, XVI Encontro Latino Americano de PósGraduação e VI Encontro de Iniciação à Docência, 2016, Vale do Paraíba. Anais.Vale do Paraíba: Universidade do Vale do Paraíba, v. 22, n. 40, p. 1-5, 2016. Disponível em: <https://doi.org/10.18066/revistaunivap.v22i40.1725.>

WEYH, A.; BARBOSA-CARVALHO, I.G.; DEL VALLE GARNERO, A. Twister Proteico: uma ferramenta lúdica envolvendo a síntese de proteínas. Revista de Ensino de Bioquímica, v. 13, n. 1, p. 58-74, 2015. Disponível em:

$<$ https://doi.org/10.16923/reb.v13i1.540.>

YOKAICHIYA, D. K.; GALEMBECK, E.; TORRES, B. B. O que alunos de diferentes cursos procuram em disciplinas extracurriculares de bioquímica?. Revista de Ensino 
de Bioquímica, v. 2, n. 1, p. 1-8, 2004. Disponível em:

$<$ https://doi.org/10.16923/reb.v2i1.17.>

\section{Agradecimentos}

À Fundação de Amparo à Ciência e Tecnologia do Estado de Pernambuco (FACEPE), ao Conselho Nacional de Desenvolvimento e Científico e Tecnológico (CNPq) e à Coordenação de Aperfeiçoamento de Pessoal de Nível Superior (CAPES) pelo auxílio financeiro e pelas bolsas concedidas. 